\title{
Expression and display of UreA of Helicobacter acinonychis on the surface of Bacillus subtilis spores
}

\author{
Krzysztof Hinc ${ }^{1,2}$, Rachele Isticato1, Marcin Dembek², Joanna Karczewska², Adam Iwanicki², \\ Grażyna Peszyńska-Sularz ${ }^{3}$, Maurilio De Felice ${ }^{1}$, Michał Obuchowski², Ezio Ricca ${ }^{1 *}$
}

\begin{abstract}
Background: The bacterial endospore (spore) has recently been proposed as a new surface display system. Antigens and enzymes have been successfully exposed on the surface layers of the Bacillus subtilis spore, but only in a few cases the efficiency of expression and the effective surface display and have been determined. We used this heterologous expression system to produce the A subunit of the urease of the animal pathogen Helicobater acinonychis. Ureases are multi-subunit enzymes with a central role in the virulence of various bacterial pathogens and necessary for colonization of the gastric mucosa by the human pathogen $H$. pylori. The urease subunit UreA has been recognized as a major antigen, able to induce high levels of protection against challenge infections.

Results: We expressed UreA from H. acinonychis on the B. subtilis spore coat by using three different spore coat proteins as carriers and compared the efficiency of surface expression and surface display obtained with the three carriers. A combination of western-, dot-blot and immunofluorescence microscopy allowed us to conclude that, when fused to CotB, UreA is displayed on the spore surface (ca. $1 \times 10^{3}$ recombinant molecules per spore), whereas when fused to CotC, although most efficiently expressed $\left(7-15 \times 10^{3}\right.$ recombinant molecules per spore) and located in the coat layer, it is not displayed on the surface. Experiments with CotG gave results similar to those with CotC, but the CotG-UreA recombinant protein appeared to be partially processed.

Conclusion: UreA was efficiently expressed on the spore coat of B. subtilis when fused to CotB, CotC or CotG. Of these three coat proteins CotC allows the highest efficiency of expression, whereas CotB is the most appropriate for the display of heterologous proteins on the spore surface.
\end{abstract}

\section{Background}

Surface display systems are a powerful biological tool with a variety of applications in the development of live vaccines, generation of biocatalysts or biosensors, treatment of microbial infections and screening of peptide libraries [1,2]. Several approaches to display heterologous proteins in bacteria and phages have been developed and extensively reviewed $[2,3]$. In general, methods to display heterologous proteins involve the construction of gene fusions that code for a chimera formed by a carrier protein that anchors a heterologous passenger protein on the cell surface [3]. Similar approaches have also

\footnotetext{
*Correspondence: ericca@unina.it

${ }^{1}$ Department of Structural and Functional Biology, Federico II University of Naples, via Cinthia 4, Naples 80126, Italy
}

been used for displaying heterologous antigens $[4,5]$ or enzymes [6,7] on the surface of endospores (spores) of Bacillus subtilis. The spore surface (spore coat) is formed by over 50 proteins organized into a inner and an outer layer. Components of the outer layer, selected for their surface location [4] or relative abundance [5-7], have been used as carrier proteins.

Spores are extremely stable life forms generated by gram-positive bacteria of the Bacillus and Clostridium genera in response to harsh environmental conditions that do not allow cell growth and survival. In the spore form these bacteria can survive indefinitely in the absence of nutrients and can resist UV irradiation, extreme temperature and exposure to lytic enzymes and toxic chemicals [8]. Spore coat proteins are produced in the bigger cell (mother cell) and assembled around the forming spore in

\section{(Naples, via Cinthia 4, Naples 80126, Italy \\ () Biomed Central}

(c) 2010 Hinc et al; licensee BioMed Central Ltd. This is an Open Access article distributed under the terms of the Creative Commons Attribution License (http://creativecommons.org/licenses/by/2.0), which permits unrestricted use, distribution, and reproduction in any medium, provided the original work is properly cited. 
the mother cell cytoplasm, thus eliminating the need of secretion signals and the constrains due to translocation across a membrane. In addition, several coat proteins are dispensable for the formation of an apparently normal spore and, for this reason, their manipulation to incorporate the heterologous part usually does not affect spore structure [9]. With respect to systems based on the use of phages or bacterial cells, the spore-display system provides also additional advantages, such as high stability and safety due to the unusual properties of this peculiar cell form [8]. The commercial use of spores of various species of the Bacillus genus as probiotics or for the oral prophylaxis of gastrointestinal disorders, clearly proves the safety of spores of these species [10].

So far, two coat proteins have been used to display heterologous antigens, $\operatorname{Cot} B$ and $\operatorname{Cot} C$. Both proteins are in the outermost layer of the coat, from where they can be extracted as $66 \mathrm{kDa}(\operatorname{CotB})$ and $12 \mathrm{kDa}(\operatorname{Cot} \mathrm{C})$ species $[11,12]$. CotB has been used to display the $C$ terminal fragment of the tetanus toxin (TTFC) [4], domains $1 \mathrm{~b}-3$ and 4 of the Protective Antigen (PA) of Bacillus anthracis [13] and the C-terminal part of the alpha toxin of Clostridium perfringens [14]. In the case of CotB-TTFC, dot blot experiments showed that each recombinant spore exposed $1.5 \times 10^{3}$ chimeric molecules [15]. CotC has been used to display the C-terminal fragment of the tetanus toxin (TTFC) [5], the B subunit of the heat-labile toxin (LTB) of Escherichia coli [5] and a tegumental protein of Clonorchis sinensis [16]. The CotC-based display on the spore surface has been found to depend on the site of insertion of the heterologous part. A 5-fold increase in the efficiency of display was observed when TTFC was located at the N-terminal end of CotC rather than at its C-terminal end [15]. The ability of recombinant spores expressing antigen to induce strong specific immune responses has highlighted the spore as a novel and promising mucosal vaccine delivery system [17]. A third coat protein, CotG [18], has also been used to display heterologous enzymes $[6,7]$.

Here we report the use of all three previously utilized coat proteins, CotB, CotC and CotG, to display UreA, a urease subunit of Helicobacter acinonychis, an animal pathogen closely related to $H$. pylori and recognized as a useful in vivo model to study $H$. pylori virulence mechanisms [19]. UreA of H. pylori has been shown to induce high levels of protection against a $H$. pylori challenge infection in vaccinated mice $[17,20,21]$. Clinical studies (phase I) based on the use of UreA of $H$. pylori as antigen have been performed [22-24] and the use of that antigen patented (OraVax Inc., Cambridge, MA, US). However, there is evidence that UreA from different Helicobacter species can induce protection against H. pylori infection $[25,26]$.

\section{Results}

\section{The UreA of Helicobacter acinonychis}

$H$. acinonychis produces a urease subunit A highly homologous to that of $H$. pylori. The UreA subunits of the two species share $96 \%$ identity with only 8 different amino acid residues out of 238. The ureA gene of $H$. acinonychis was PCR amplified and cloned in Escherichia coli in frame with a 6xHis tag under the transcriptional control of an inducible ara promoter. The protein was over-expressed, purified on Ni-columns and used to raise polyclonal antibody in mice. The obtained antiUreA serum recognized UreA of $H$. pylori (data not shown), suggesting that the $H$. acinonychis protein can be used as an antigen to develop a new spore-based vaccine against $H$. pylori. The anti-UreA antibody failed to react against proteins extracted from Bacillus subtilis or Escherichia coli (data not shown), indicating that the recognition of UreA of $H$. acinonychis and $H$. pylori is specific and that the signal observed with $E$. coli expressing ureA of $H$. acinonychis is exclusively due to the heterologous protein.

\section{Construction and chromosomal integration of gene fusions}

To obtain recombinant $B$. subtilis spores expressing UreA on their surface we used three $\cot$ proteins, $C$ otB, CotC and CotG as carrier proteins. To this aim the coding part of the ureA gene of $H$. acinonychis was fused in frame with the coding part of $\cot B, \cot C$ or $\cot G$, as specified below. All gene fusions retained the promoter of the cot gene to ensure proper timing of expression during the sporulation process (Fig. 1). Genetic stability was obtained by integrating the gene fusions on the B. subtilis chromosome into the coding sequence of the nonessential gene amyE [27].

The $C$ terminus of CotB is formed of three 27 amino acid repeats that confer genetic instability to chimeric proteins containing them [9]. For this reason, when CotB was used as a carrier, DNA encoding the three repeats was not included in the gene fusions and only DNA encoding the $\mathrm{N}$-terminal 275 amino acid residues of CotB was used (Fig. 1). When CotC or CotG were used as carriers, DNA encoding the entire Cot proteins was used (Fig. 1).

As heterologous part we initially used the entire UreA subunit of 238 amino acids. However, while its fusion with CotG produced a stable chimeric protein (see below), with $\operatorname{Cot} B$ and $\operatorname{Cot} C$ we failed to observe any fusion product. For this reason we fused to $\operatorname{Cot} B$ and CotC a shorter form of UreA, lacking 49 amino acids at its $\mathrm{N}$-terminal end. With the shorter form of the antigen (ureA1 in Fig. 1), stable chimeric proteins were produced with CotB and CotC (see below). 


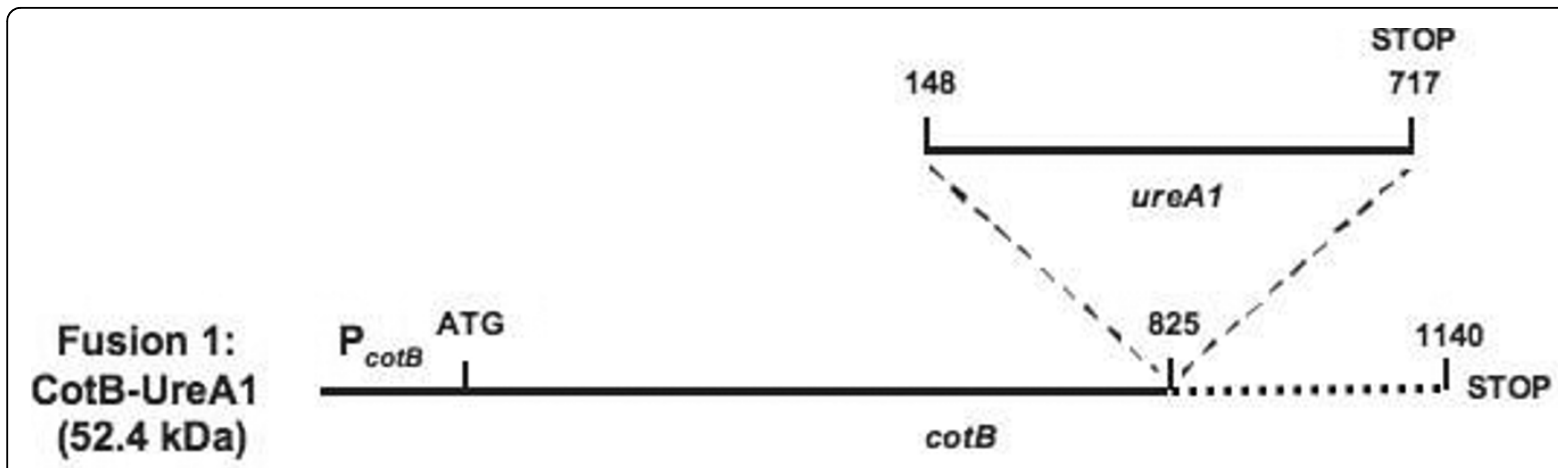

Fusion 2:

CotC-UreA1 (30.0 kDa)

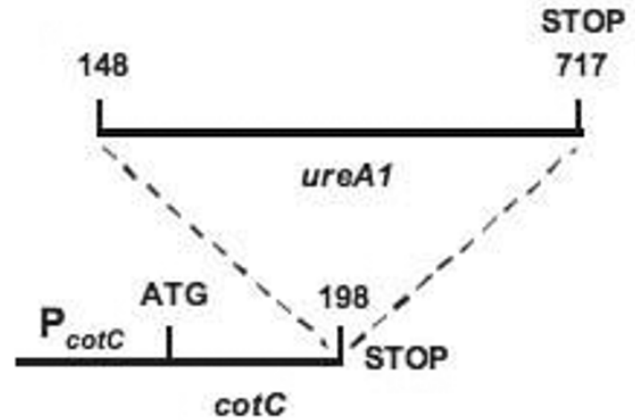

Fusion 3: CotG-UreA (50.6 kDa)

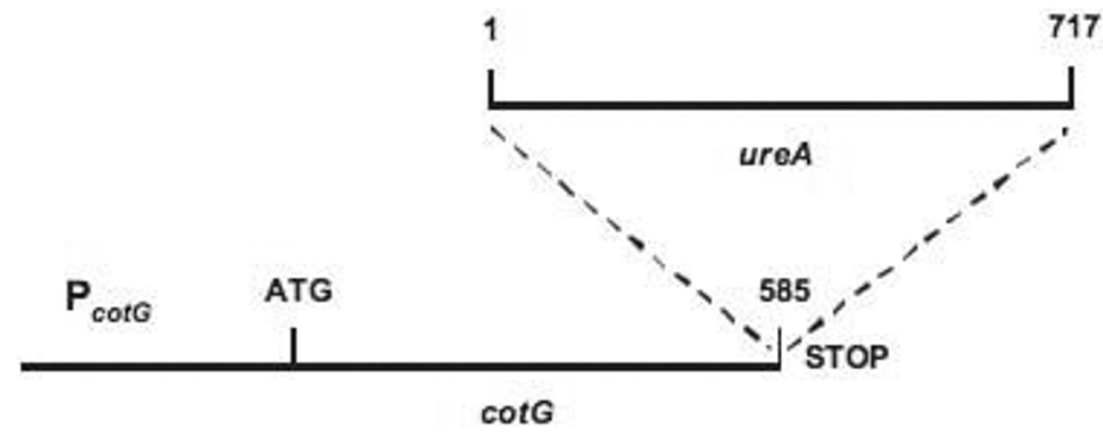

Figure 1 Schematic representation of the three gene fusions obtained. Either the entire coding region of the ureA gene (1-717) or part of it (148-717) was cloned in frame to nucleotide 825 of $\cot B$, to nucleotide 198 of $\cot C$ and to nucleotide 585 of $\cot G$. In Fusion 1 the dashed line represents the region of CotB not included in the chimeric protein (see text).

Fusion 1 was obtained cloning ureA1 (570 bp) in frame with the serine codon at position 825 of $\cot B$; Fusion 2 was constructed cloning ureA1 in frame with the tyrosine codon at position 198 of $\cot C$; and Fusion 3 was obtained cloning a 717 bp DNA fragment containing the entire $u r e A$ gene in frame with the lysine codon at position 585 of $\cot G$ (Fig. 1).

All gene fusions were integrated on the B. subtilis chromosome and individual clones for each transformation, tested by PCR (not shown), were named KH17 (Fusion 1), KH10 (Fusion 2) and KH23 (Fusion 3) and used for further analysis.

The three recombinant strains and their isogenic parental strain PY79 showed comparable sporulation and germination efficiencies and their spores were equally resistant to chloroform and lysozyme treatment (not shown). Therefore, limited to the spore properties that we have analyzed, the presence of Cot-UreA fusions does not affect spore structure or functionality.

\section{Surface expression}

To verify that the gene fusions were localized on the spore coat, we used a western blot approach using antiCotB, anti-CotC, anti-CotG and anti-UreA antibodies. To perform the western blot experiments Fusion 2 was moved by chromosomal DNA-mediated transformations into isogenic B. subtilis strains deleted of $\cot C$ and/or $\cot U$ genes, since it has been previously reported that 
the presence of the wild type allele of $\cot C$ or of its homolog $\cot U$, may reduce the efficiency of antigen display $[4,5]$. For the same reason Fusion 3 was moved into an isogenic strain deleted of $\cot G$ [18], while Fusion 1 was only analyzed in otherwise wild type cells, since it has been reported that the absence of a $\cot B$ wild type allele impairs display of the recombinant form of CotB [4].

Western blot analysis of spore coat proteins purified from wild type and recombinant strains carrying Fusion 1 revealed the presence of an about $55-\mathrm{kDa}$ band which reacted with both UreA- and CotB-specific antibodies (Fig. 2AB). A 66-kDa band, only reacting with CotB-specific antibody, was present in extracts from wild type and recombinant spores (Fig. 2AB), indicating the presence of intact $C$ ot $B$ molecules in the spore coat together with CotB-UreA1 fusion protein.

The analysis of strains carrying Fusion 2 showed the presence of an about 30-kDa band which reacted with both UreA- and CotC-specific antibodies (Fig. 3AB). A standard pattern of $\operatorname{Cot} C$ and $\operatorname{Cot} U$ proteins $[11,12]$ was observed in wild type spore with and without Fusion 2 (Fig. 3A, lanes 1-2). In agreement with a previous report [15], the fusion of a heterologous protein at the $\mathrm{C}$ terminus of $\operatorname{Cot} C$ impaired the formation of $\operatorname{Cot} C$ homodimer and CotC-CotU heterodimer. As a consequence, when fused to UreA1 CotC was only found as a monomer. Only the recombinant protein was observed in strains carrying either a null mutation in $\cot C$ and/or $\cot U$ (Fig. 3A, lanes 4-6).

The analysis of strains carrying Fusion 3 showed that in the presence of a wild type $\cot G$ allele the chimeric protein was not expressed (data not shown). However, the analysis of the strain carrying the gene fusion and a deletion of the wild type $\cot G$ gene, showed the appearance of a $55-\mathrm{kDa}$ band able to react with both UreAand CotG-specific antibodies (Fig. 4AB). A 32-kDa band, corresponding to CotG [24], was observed in wild type spores (Fig. 4A), while a band of about $30 \mathrm{kDa}$ only reacting with anti-UreA antibody was present in coat extracts of a strain carrying a deletion of the $\cot G$ gene and Fusion 3 (Fig. 4B, lane 3). This band is not (or very weakly) recognized by anti-CotG antibody and is bigger that purified UreA (Fig. 4B, lane 4), we therefore hypothesize that it is a degradation product of CotGUreA and contains only a small fragment of CotG.

In all three cases the recombinant proteins observed showed apparent molecular weights that correlated well with the deduced molecular weights: Fusion 1, 52.4/55; Fusion 2, 30/30; Fusion 3, 50.6/55 (deduced/apparent $\mathrm{kDa})$.

\section{Surface display}

To analyse the surface exposure of Cot-fused UreA molecules, sporulating cells of wild type and the isogenic recombinant strains were analyzed by

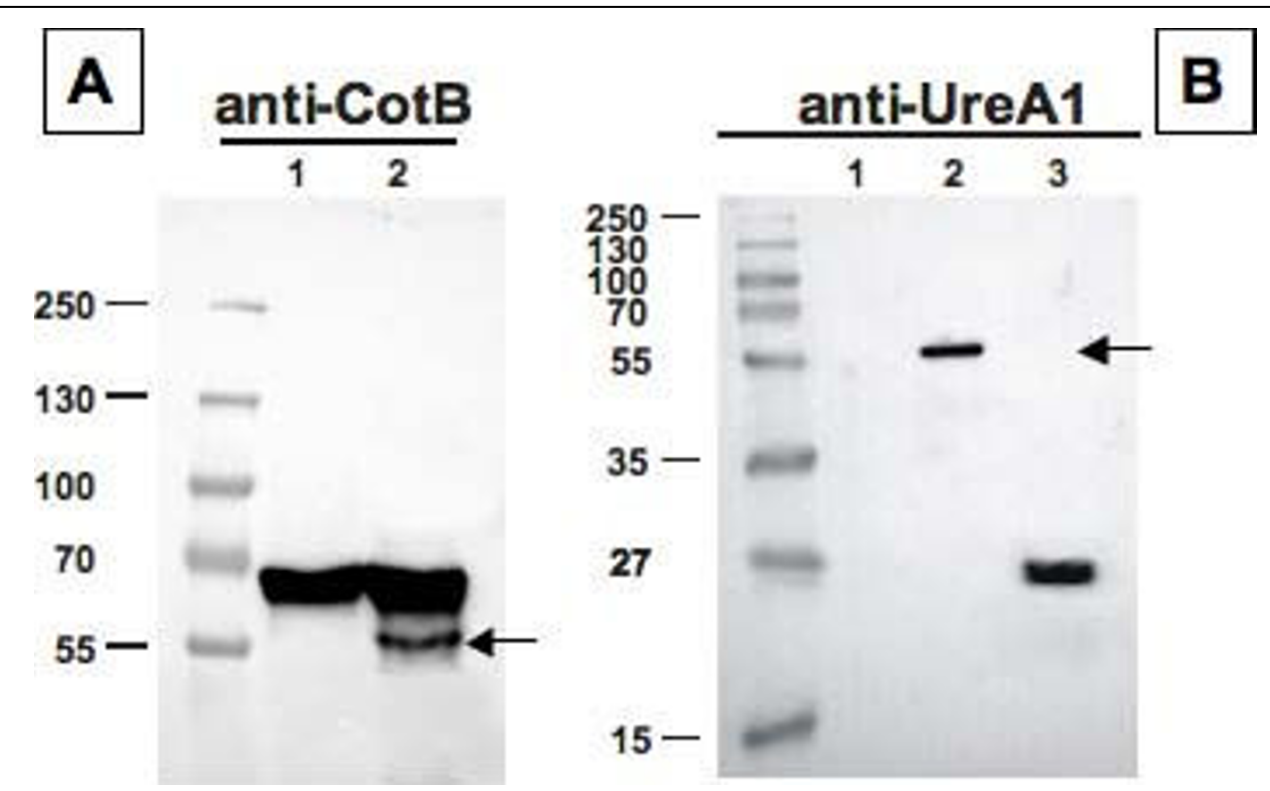

Figure 2 Western blot analysis of Fusion 1 (CotB-UreA1) performed with anti-CotB (A) or anti-UreA (B) of spore coat proteins extracted from strains PY79 (lanes 1) and KH17 (PY79 carrying cotB::ureA1) (lanes 2). In both panels arrows point to fusion proteins. Purified UreA was run in lane 3 of panels B. Twenty five micrograms of total proteins were separated on either 8\% (A), 12\% (B) polyacrylamide gels, electrotransferred to nitrocellulose membranes and reacted with primary antibodies and then with peroxidase-conjugated secondary antibodies and visualized by the enhanced chemiluminescence method. 


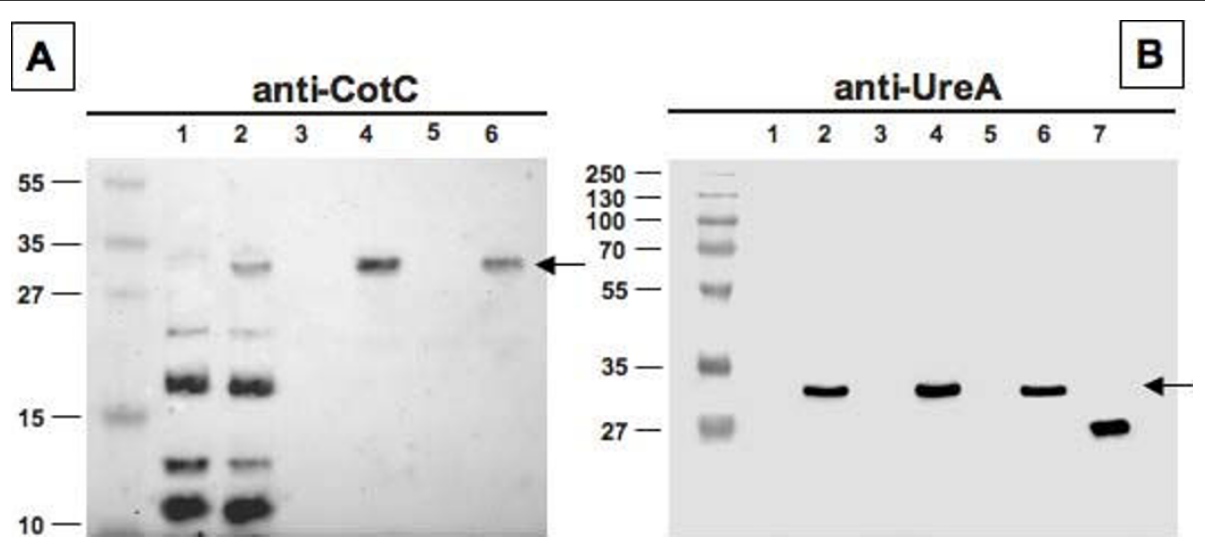

Figure 3 Western blot analysis of Fusion 2 (CotC-UreA1) performed with anti-CotC (A) or anti-UreA (B) of spore coat proteins extracted from strains PY79 (lanes 1), KH10 (PY79 carrying cotC::ureA1) (lanes 2), RH101 (PY79 cotC:::spc) (lanes 3), KH11 (PY79 cotC:: spc cotC:::ureA1) (lanes 4), RH209 (PY79 cotC:::spc cotU::erm) (lanes 5) and KH12 (PY79 cotC:::spc cotU::erm cotC:::ureA1) (lanes 6). In both panels arrows point to fusion proteins. Purified UreA was run in lane 7 of panels B. Twenty five micrograms of total proteins were separated on either 15\% (A) or 12\% (B) polyacrylamide gels, electrotransferred to nitrocellulose membranes and reacted with primary antibodies and then with peroxidase-conjugated secondary antibodies and visualized by the enhanced chemiluminescence method.

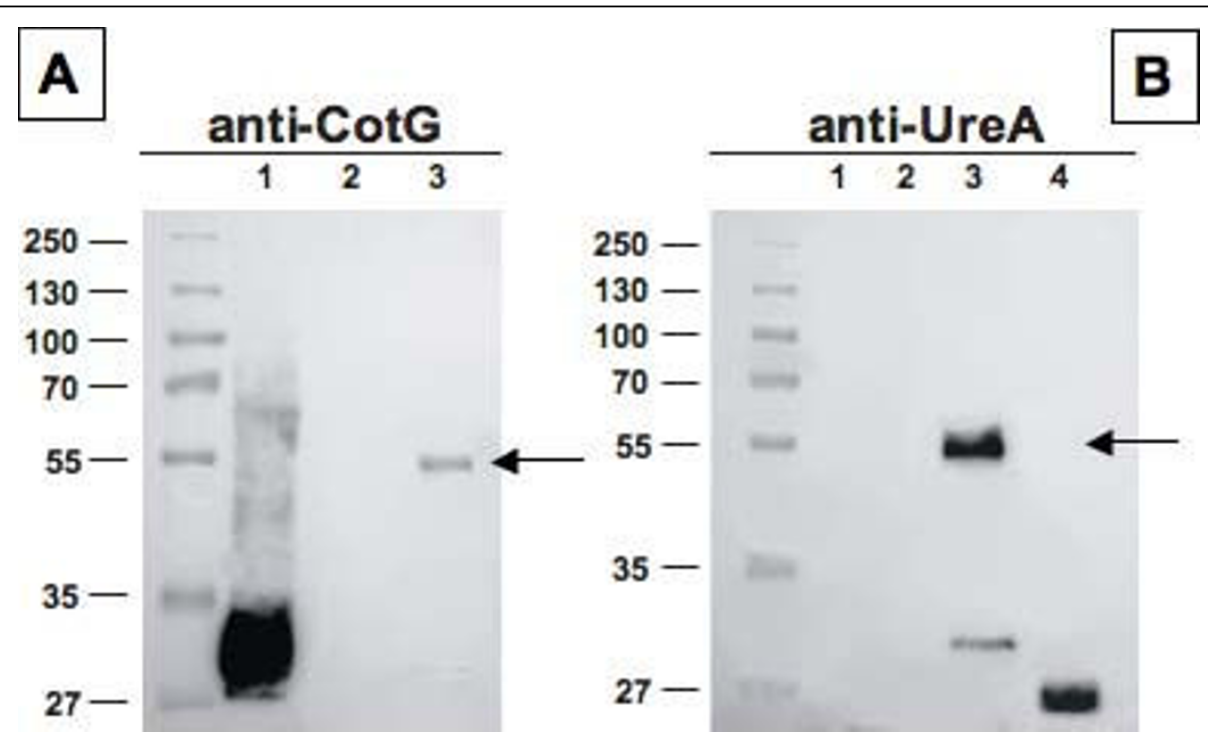

Figure 4 Western blot analysis of Fusion 3 (CotG-UreA) performed with anti-CotG (A) or anti-UreA (B) of spore coat proteins extracted from strains PY79 (lanes 1), ER203 (PY79 cotG::erm) (lanes 2) and KH23 (PY79 cotG::erm cotG::ureA) (lanes 3). In both panels arrows point to fusion proteins. Purified UreA was run in lane 4 of panel F. Twenty five micrograms of total proteins were separated on either 15\% (A) or 12\% (B) polyacrylamide gels, electrotransferred to nitrocellulose membranes and reacted with primary antibodies and then with peroxidase-

conjugated secondary antibodies and visualized by the enhanced chemiluminescence method.

immunofluorescence microscopy with UreA-specific primary antibodies and anti-mouse IgG-TR (Texas Red) (Santa Cruz Biotechnology Inc.) as secondary antibody. While for Fusion 1 (CotB-UreA1) a weak fluorescence signal was observed around free, mature, spores (Fig. 5), for Fusion 2 (CotC-UreA1) and Fusion 3 (CotG-UreA) fluorescence was observed around forming spores (still inside mother cells) but not around free spores (Fig. 5). These results indicate that in the case of CotB-UreA1 the spore-exposed antigen is accessible to the antibody, while on spores carrying CotC- or CotG-UreA the antigen is present (since it can be extracted and visualized by western blot) but not accessible to the interaction with the antibody.

\section{Efficiency of expression}

A quantitative determination of the amount of UreA present on B. subtilis spores was obtained by dot blot 


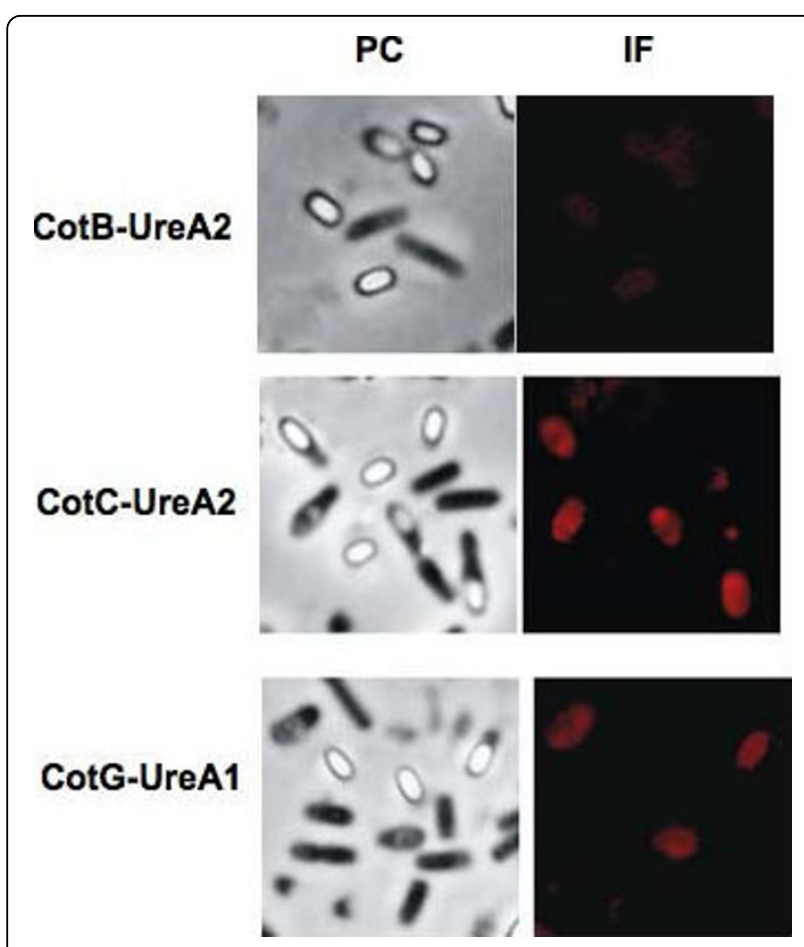

Figure 5 Immunofluorescence microscopy analysis. Sporulating cells and free spores are visualized by phase contrast (PC) and by immunofluorescence (IF) microscopy. Samples were labeled with mouse anti-UreA antisera, followed by anti-mouse IgG-TR (Texas Red or sulphorhodamine 101 acid chloride) conjugates. The same exposure time was used for all IF samples. experiments using serial dilutions of purified UreA and of coat proteins extracted from spores of the wild type and the recombinant strains. Proteins were reacted with antiUreA antibody, then with alkaline phosphatase-conjugated secondary antibodies and colour developed by the BCIP/NBT system (Bio-Rad) (Fig. 6). A densitometric analysis indicated that the CotB-UreA1 fusion protein amounted to $0.1 \%$ of total coat proteins extracted, CotCUreA 1 between 0.4 and $0.8 \%$, depending on the genetic background utilized, and CotG-UreA to $0.5 \%$ (Table 1). Considering the average amount of total proteins extracted in our experimental conditions from each spore $[4.6 \mathrm{mg} / \mathrm{ml}( \pm 0.23)$ for strain $\mathrm{KH} 17,4.9 \mathrm{mg} / \mathrm{ml}( \pm$ $0.26)$ for strain $\mathrm{KH} 10,5.1 \mathrm{mg} / \mathrm{ml}( \pm 0.18)$ for strain $\mathrm{KH} 11,5.1 \mathrm{mg} / \mathrm{ml}( \pm 0.25)$ for strain $\mathrm{KH} 12$ and $4.7 \mathrm{mg} / \mathrm{ml}$ $( \pm 0.31)$ for strain $\mathrm{KH} 23]$, we calculated that the number of recombinant proteins extracted from each spore ranged between $1.1 \times 10^{3}$ (KH17) and $15 \times 10^{3}$ (KH11) (Table 1).

\section{Discussion}

The A subunit of the urease (UreA) of various species of the Helicobacter genus, has long been recognized as an antigen able to induce high levels of protection against the infection by the human pathogen $H$. pylori $[17,20,21,25,26]$. The use of spores as mucosal vaccine vehicles has been tested with various antigens $[4,5,13,14,16]$ and recently reviewed [28]. Expression of UreA on the spore was achieved by using three different

\begin{tabular}{|c|c|c|c|c|c|c|c|c|c|c|c|c|c|c|c|c|}
\hline A & & & & & B & & & & & & & C & & & & \\
\hline $\mathrm{ng}$ & 1 & 2 & 3 & $\mu g$ & $\mathrm{ng}$ & 1 & 2 & 3 & 4 & 5 & $\mu g$ & $\mathrm{ng}$ & 1 & 2 & 3 & $\mu g$ \\
\hline 50.00 & ○ & & • & 20.00 & 50.00 & 0 & & 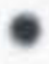 & C & e & 5.000 & 50.00 & 8 & & 0 & 10.00 \\
\hline 25.00 & e & & e & 10.00 & 25.00 & P & & 루 & 8 & $\theta$ & 2.500 & 25.00 & ? & & 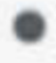 & 5.000 \\
\hline 12.50 & a & & 6 & 5.000 & 12.50 & 항 & & 울 & e & 6 & 1.125 & 12.50 & $\theta$ & & e & 2.500 \\
\hline 6.250 & 9 & & a & 2.500 & 6.250 & c & & 8 & 후 & 45 & 0.625 & 6.250 & 8 & & e & 1.250 \\
\hline 3.125 & 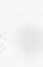 & & & 1.250 & 3.125 & 6 & & tef & 9 & 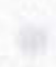 & 0.312 & 3.125 & 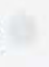 & & $\theta$ & 0.625 \\
\hline 1.562 & & & & 0.625 & 1.562 & teft & & & a & & 0.156 & 1.562 & & & 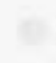 & 0.312 \\
\hline $\begin{array}{l}\text { Figure } \\
\text { lane } 3 \text { ), } \\
\text { contain } \\
\text { respecti }\end{array}$ & & & & $\begin{array}{l}\text { led wit } \\
\text { 3-5) an } \\
110(\mathrm{PY} \\
\mathrm{ng}, \mathrm{lar}\end{array}$ & $\begin{array}{l}\text { cated c } \\
\text { (C, lan } \\
\text { cotC::ure } \\
\text { anels) }\end{array}$ & eAl) & & & & es $(1$ & $\begin{array}{l}\mu \mathrm{\mu g}) \text { ex } \\
\text { ne } 2 \text { in } \\
\text { and } K\end{array}$ & $\begin{array}{l}\text { om spor } \\
\text { s). In pan } \\
\text { cotC:Ispc }\end{array}$ & & & $\begin{array}{l}\text { usiol } \\
\text { and } \\
\text { ureA }\end{array}$ & $\begin{array}{l}n \mathbf{1} \text { ( (A, } \\
5 \\
1),\end{array}$ \\
\hline
\end{tabular}


Table 1 Densitometric analysisa ${ }^{a}$

\begin{tabular}{|c|c|c|c|c|}
\hline UreA source & $\begin{array}{c}\text { Amount of proteins } \\
\text { used (ng) }\end{array}$ & $\begin{array}{l}\text { Density in } \mathrm{OD} / \mathrm{mm}^{2} \\
\text { (standard deviation) }\end{array}$ & $\begin{array}{l}\text { UreA concentration }(\mathrm{ng}) \\
\text { in extracts }(\% \text { of total) }\end{array}$ & $\begin{array}{l}\mathrm{n}^{\circ} \text { of recombinant proteins } \\
\text { extracted from each spore }\end{array}$ \\
\hline \multicolumn{5}{|l|}{ Fusion 1} \\
\hline \multirow[t]{3}{*}{ Purified UreA } & $6.25 \mathrm{ng}$ & $38.9( \pm 0.08)$ & NA & \\
\hline & $3.12 \mathrm{ng}$ & $19,1( \pm 0.11)$ & NA & \\
\hline & $1.56 \mathrm{ng}$ & $9.8( \pm 0.06)$ & NA & \\
\hline \multirow[t]{3}{*}{ KH17 (CotB-UreA1) } & $5.00 \mu \mathrm{g}$ & $30,4( \pm 0,03)$ & $4.93(0.10)$ & \\
\hline & $2.50 \mu \mathrm{g}$ & $15,1( \pm 0,01)$ & $2.51(0.10)$ & $1.1 \times 10^{3}$ \\
\hline & $1.25 \mu \mathrm{g}$ & $7,4( \pm 0,02)$ & $1.12(0.09)$ & \\
\hline \multicolumn{5}{|l|}{ Fusion 2} \\
\hline \multirow[t]{3}{*}{ Purified UreA } & $25.0 \mathrm{ng}$ & $127.8( \pm 0.02)$ & NA & \\
\hline & $12.5 \mathrm{ng}$ & $63,3( \pm 0.01)$ & NA & \\
\hline & $6.25 \mathrm{ng}$ & $32.1( \pm 0.04)$ & NA & \\
\hline \multirow{3}{*}{$\begin{array}{l}\text { KH10 (CotC-UreA1 wt } \\
\text { background) }\end{array}$} & $2.50 \mu \mathrm{g}$ & $99.1( \pm 0.07)$ & $16.55(0.66)$ & \\
\hline & $1.25 \mu \mathrm{g}$ & $48.6( \pm 0.09)$ & $8.14(0.65)$ & $9.6 \times 10^{3}$ \\
\hline & $0.625 \mu \mathrm{g}$ & $23.6( \pm 0.10)$ & $4.37(0.70)$ & \\
\hline \multirow{3}{*}{$\begin{array}{l}\text { KH11 (CotC-UreA1 } \cot \mathrm{C} \\
\text { background) }\end{array}$} & $2.50 \mu \mathrm{g}$ & $117.4( \pm 0.03)$ & $20.82(0.83)$ & \\
\hline & $1.25 \mu \mathrm{g}$ & $57.7( \pm 0.08)$ & $10.35(0.83)$ & $15 \times 10^{3}$ \\
\hline & $0.625 \mu \mathrm{g}$ & $28.9( \pm 0.21)$ & $5.15(0.82)$ & \\
\hline \multirow{3}{*}{$\begin{array}{l}\mathrm{KH} 12 \text { (CotC-UreA1 } \cot \mathrm{C} \cot U \\
\text { background) }\end{array}$} & $2.50 \mu \mathrm{g}$ & $63.9( \pm 0.03)$ & $11.10(0.44)$ & \\
\hline & $1.25 \mu \mathrm{g}$ & $30.7( \pm 0.01)$ & $5.71(0.46)$ & $7.2 \times 10^{3}$ \\
\hline & $0.625 \mu \mathrm{g}$ & $15.4( \pm 0.03)$ & $2.93(0.47)$ & \\
\hline \multicolumn{5}{|l|}{ Fusion 3} \\
\hline \multirow[t]{3}{*}{ Purified UreA } & $25.0 \mathrm{ng}$ & $131.2( \pm 0.30)$ & NA & \\
\hline & $12.5 \mathrm{ng}$ & $64,1( \pm 0.11)$ & NA & \\
\hline & $6.25 \mathrm{ng}$ & $31.6( \pm 0.22)$ & NA & \\
\hline \multirow{3}{*}{$\begin{array}{l}\text { KH23 (CotG-UreA cotG } \\
\text { background) }\end{array}$} & $5.00 \mu \mathrm{g}$ & $135,7( \pm 0.25)$ & $28.42(0.57)$ & \\
\hline & $2.50 \mu \mathrm{g}$ & $68,2( \pm 0.37)$ & $14.73(0.59)$ & $5.3 \times 10^{3}$ \\
\hline & $1.25 \mu \mathrm{g}$ & $34,7( \pm 0,05)$ & $7.15(0.57)$ & \\
\hline
\end{tabular}

spore coat proteins as carriers. All three proteins, CotB, CotC and CotG, were previously used to express and/or display heterologous proteins on the B. subtilis spore surface. In particular, $\operatorname{Cot} B$ and $\operatorname{Cot} C$ were used to express heterologous antigens $[4,5,13,14,16]$, while CotG was used to express heterologous enzymes [6,7]. Our initial attempts of using the entire UreA subunit of 239 amino acid residues were not successful with $C$ otB and CotC as carriers. However, we successfully used a shorter version of UreA, indicated here as UreA1 and lacking 49 amino acids at the $\mathrm{N}$-terminal end of the antigen, with both $\mathrm{Cot} B$ and CotC. UreA1, contains all six potentially most immunogenic regions of UreA that are all included between residue 64 and residue 189 , as determined by analysis of the UreA protein sequence by the Antigen program (a part of EMBOSS package).

A first conclusion of this study comes from the analysis of the strain carrying the $\operatorname{cotB}:: u r e A 1$ gene fusion. Immunofluorescence experiments showed that, when fused to CotB, UreA1 is displayed on the spore surface, and dot-blot data followed by densitometric analysis indicated that $1.1 \times 10^{3} \mathrm{CotB}$-UreA1 molecules were extracted from each purified spore. A previous study, in which $\mathrm{CotB}$ was used to express the $C$ fragment of the tetanus toxin (TTFC), showed that the heterologous part was displayed on the spore surface and that $1.5 \times$ $10^{3}$ recombinant proteins were extracted from each spore [4]. The similarities observed between spores carrying CotB-UreA1 and CotB-TTFC suggest that surface display and amount of recombinant protein expressed depends mainly on CotB and is not influenced by the nature of the heterologous part.

The functionality of CotC as a carrier appears, instead, to be dependent on the heterologous protein. When fused to CotC, UreA1 is efficiently expressed and is present on the coat but is not displayed on the spore surface. Two other antigens, TTFC and the B subunit of the heatlabile toxin of E. coli (LTB) were previously reported as 
surface displayed when fused to CotC [5]. However, the number of recombinant molecules extracted from each purified spore is reproducibly higher with CotC than with other two coat proteins as carriers and ranges from $7.2 \times 10^{3}$ and $15 \times 10^{3}$ depending on the genetic background of the host cell (Table 1 ).

Of the three coat proteins tested, CotG is the only one that allowed the expression of the entire UreA protein. UreA is not displayed but is present in the coat and is extracted in amounts about intermediate between those observed with the other two coat proteins (Table 1). However, the recombinant CotG-UreA protein is partially processed. While most CotG-UreA molecules have a size of about $55 \mathrm{kDa}$, that correlates well with the deduced size of $50.6 \mathrm{kDa}$, a fraction of these molecules is probably processed to originate a protein of about $30 \mathrm{kDa}$. This protein is smaller than UreA alone (Fig. 4B), is recognized by anti-UreA antibody and not recognized, or very poorly recognized by anti-CotG antidody (Fig. 4AB). We speculate that either the CotG-UreA chimera is unstable and partially degraded or that a proteolytic cleavage occurs within the CotG part of the chimera. In this case the $30 \mathrm{kDa}$ protein would be formed by UreA and by a small fragment of CotG, explaining the size and the weak, if any, reactivity with anti-CotG antibody. However, a proteolytic processing has never been reported for wild type CotG. Additional experiments will be needed to explain the observed phenomenon and identify the presumptive cleavage site.

It is interesting to note that, for the various coat proteins used as carriers, the genetic background of the host cell differently affects the surface expression of the fusion proteins. CotC-based chimeras are better expressed in the absence of a wild type allele of $\cot C$ but in the presence of a wild type allele of $\cot U$, coding for a $\operatorname{Cot} C$ homolog, known to interact with $\operatorname{Cot} C$ [12], while CotB-UreA1 is only expressed in the presence of a wild type allele of $\cot B$ and, on the contrary, CotG-UreA is only expressed in the absence of a wild type allele of $\cot G$.

Results reported here point to $\operatorname{Cot} B$ and $\operatorname{Cot} C$ as the most appropriate carriers for UreA display on the spore surface and for its efficient expression, respectively. Immunological experiments will now be needed to assess whether the surface display of an antigen is an essential requisite for inducing a protective immune response or whether it is preferable to have the highest possible number of recombinant molecules on the spore coat layers even though these are not exposed on the spore surface. An antigen that is not directly exposed on the spore surface but is very abundant in the underneath protein layers, could be protected from the gastric enzymes and result immunologically more active.

\section{Conclusions}

1) UreA of $H$. acinonychis was expressed on the spore of B. subtilis, a new heterologous expression system recently utilized to display antigens and enzymes [28]. Three different spore surface proteins were used as carrier to express UreA: CotB, CotC or CotG.

2) Among the three carriers, CotC was shown to allow the highest efficiency of expression. A large amount of its passenger protein was found to be located within the coat, however it was not displayed outside the spore. On the contrary, the level of expression of CotB-fused UreA was lower, but in this case the passenger protein was exposed on the spore surface and thus CotB resulted as a more appropriate carrier for the display of heterologous proteins. Finally CotG gave results similar to those with CotC, but the CotG-UreA recombinant protein appeared to be partially processed.

\section{Methods}

\section{Bacterial strains and transformation}

Bacillus subtilis strains used in this study are listed in Table 2. Plasmid amplification for nucleotide sequencing and subcloning experiments were performed with Escherichia coli strain DH5 $\alpha$ [29]. Bacterial strains were transformed by previously described procedures: $\mathrm{CaCl}_{2}$ mediated transformation of E. coli competent cells [29] and transformation of B. subtilis [30].

\section{Construction of gene fusions}

To obtain various gene fusions DNA coding for the selected coat protein was PCR amplified using the $B$. subtilis chromosome as a template and as primers oligonucleotide pairs cotB-up/cotB-dn, $\cot C-u p / \cot C-d n$ and cotG-up and cotG-dn (Table 3) for fusions cotB::ureA1, $\cot C:$ :ure $A 1$ and $\cot$-ureA, respectively. Amplification products of $1100 \mathrm{bp}$ (cotB::ureA1), $393 \mathrm{bp}$ (cotC::ureA1) and 1043 bp ( $\operatorname{cotG::ureA)}$ were obtained and cloned into the pGem-T easy vector (Promega) or pDL vector

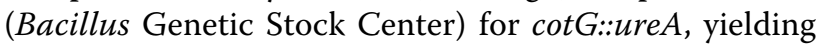
plasmids pGEM-CotB, pGEM-CotC and pDL-CotG.

Table 2 Strain list

\begin{tabular}{|c|c|c|}
\hline Strain & Relevant genotype & Source \\
\hline PY79 & prototrophic & [34] \\
\hline KH17 & amyE::cotB::UreA1 & This work \\
\hline $\mathrm{RH} 101$ & $\cot C:: s p C$ & [11] \\
\hline $\mathrm{RH} 209$ & cotC::spc cotU::neo & [15] \\
\hline $\mathrm{KH} 10$ & amyE:::cotC:::UreA1 & This work \\
\hline $\mathrm{KH} 11$ & cotC:::spc amyE:::cotC:::UreA1 & This work \\
\hline $\mathrm{KH} 12$ & $\operatorname{cotC::spc\operatorname {cot}U::neo}$ amyE:::cotC:::UreA1 & This work \\
\hline ER203 & cotG.:erm & {$[18]$} \\
\hline $\mathrm{KH} 23$ & amyE::-cotG.::ureA cotG.::erm: & This work \\
\hline
\end{tabular}


Table 3 Oligonucleotides list

\begin{tabular}{|c|c|c|}
\hline Name & Sequence $\left(5^{\prime}-3^{\prime}\right)$ & Restriction site \\
\hline cotB-up & AAGCTTACGGATTAGGCCGTTTGTC & HindIII \\
\hline cotB-dn & GATATCGGATGATTGATCATCTGAAG & EcoRV \\
\hline cotC-up & ACCCAAGCTTTGTAGGATAAATCGTTTG & HindIII \\
\hline $\cot C-d n$ & GATATCGTAGTGTTTTTTATGCTT & EcoRV \\
\hline cotG-up & CCCGAATTCCGAGAAAAAATCC & EcoRl \\
\hline $\operatorname{cotG}-d n$ & CTTGGATCCTTTGTATTCTITITGACTAC & $\mathrm{BamHI}$ \\
\hline ureA-up & GAGGGATCCATGAAACTCACCCCAAAAG & BamHI \\
\hline ureA-dn & CGCGAGCTCTAGGGCCATACATAGAAAC & Sacl \\
\hline ureA1-up & GAAGCGGATATCGGTAAAAAGACTGCG & EcoRV \\
\hline ureA1-dn & GGGCCATACACTAGTACATATTCTITTCTGCTAATC & Spel \\
\hline hisureA-up & CTCGGTACCTTCTTTTCTGCTAATCTTITTTC & Kpnl \\
\hline hisureA-dn & TATGCTAGCATGCATCATCACCATCACCATCACTCGAAACTCACCCCAAAAGAG & Nhel \\
\hline
\end{tabular}

In bold are the recognition sites for the restriction enzymes indicated in the table.

A 625 bp DNA fragment coding for a fragment of UreA was PCR amplified using $H$. acinonychis chromosome as a template and oligonucleotides ureA1-up and ureA1-dn (Table 3 ) as primers. The PCR product was sequentially digested with EcoRV and SpeI and cloned in frame to the 3 ' end of the $\cot B$ and $\cot C$ genes carried by plasmids pGEM-CotB and pGEM-CotC, yielding plasmids pKH09 and pKH02, respectively. Plasmids pKH09 and pKH02 were digested with HindIII and EcoRI and fragments carrying the gene fusions gel-purified and ligated into plasmid pDG364 [27] previously digested with the same two restriction enzymes, yielding plasmids $\mathrm{pKH} 14$ and $\mathrm{pKH} 03$, respectively. A 748 bp DNA fragment coding for the entire UreA subunit was PCR amplified using $H$. acinonychis chromosome as a template and oligonucleotides ureA-up and ureA-dn as primers (Table 3). The PCR product was sequentially digested with $\mathrm{Bam} \mathrm{HI}$ and $\mathrm{SacI}$ and cloned in frame to the 3' end of the $\cot G$ gene carried by plasmid pDL-CotG yielding plasmid pKH20.

\section{Chromosomal integration}

Plasmids pKH14 and pKH03 were linearized by digestion with $\mathrm{XhoI}$ while plasmid pKH20 was linearized by digestion with PstI. Linearized DNA was used to transform competent cells of the B. subtilis strain PY79. Chloramphenicol-resistant $\left(\mathrm{Cm}^{\mathrm{R}}\right)$ clones were the result of a double-crossover recombination event, resulting in the interruption of the non-essential $a m y E$ gene on the B. subtilis chromosome. Several $\mathrm{Cm}^{\mathrm{R}}$ clones were tested by PCR using chromosomal DNA as a template and oligonucleotides AmyS and AmyA [9] to prime the reaction. Three clones, one for each transformation, were selected, called KH17 (from pKH14, Fusion 1), KH10 (from pKH03, Fusion 2), and KH21 (from pKH20, Fusion 3) and kept for further studies.
Chromosomal DNA extracted from strain KH10 was moved into a isogenic $\cot C$ null strain RH101 [5], and isogenic $\cot C$ cot $U$ double null strain RH209 [15] by chromosomal DNA-mediated transformation [27] yielding strains $\mathrm{KH} 11$ and $\mathrm{KH} 12$, respectively. Chromosomal DNA extracted from strain KH21 was used to transform the isogenic cotG null strain ER203 [18], yielding strains KH23.

\section{Preparation of spores}

Sporulation was induced by the exhaustion method in DS (Difco-Sporulation) medium as described elsewhere [31]. Sporulating cultures were harvested $24 \mathrm{~h}$ after the initiation of sporulation and purified using a lysozyme treatment to break residual sporangial cell followed by washing steps in $1 \mathrm{M} \mathrm{NaCl}, 1 \mathrm{M} \mathrm{KCl}$ and water (twotimes), as described previously [31]. PMSF (0.05 M) was included to inhibit proteolysis. After the final suspension in water, spores were treated at $65^{\circ} \mathrm{C}$ for $1 \mathrm{~h}$ to kill residual cell. The spore suspension was titrated immediately for $\mathrm{CFU} / \mathrm{ml}$ before freezing at $-20^{\circ} \mathrm{C}$. By this method we could reliably produce $6 \times 10^{10}$ spores per liter of DSM culture. Sporulation and germination efficiencies were measured as previously reported [27]. Alanine and asparagine were used to induce germination.

\section{Extraction of spore coat proteins}

Spore coat proteins were extracted from $50 \mu \mathrm{l}$ of a suspensions of spores at high density $\left(1 \times 10^{10}\right.$ spores per $\mathrm{ml}$ ) using a Decoating extraction buffer as described elsewhere [32]. Extracted proteins were assessed for integrity by SDS-polyacrylamide gel electrophoresis (PAGE) and for concentration by two independent methods: the Pierce BCA Protein Assay (Pierce) and the BioRad DC Protein Assay kit (Bio-Rad). 


\section{Western and dot blot analyses}

Extracted proteins were separated in $8 \%, 12 \%$ or $15 \%$ denaturing polyacrylamide gels, electrotransferred to nitrocellulose filters (PerkinElmer) and used for Western blot analysis by standard procedures. Western blot filters were visualized by the enhanced chemiluminescence (PerkinElmer) method as specified by the manufacturer. Serial dilutions of extracted proteins and of purified UreA were used for dot blot analysis. The filters were then visualized by the enhanced chemiluminescence (PerkinElmer) method and subjected to densitometric analysis with Chemidoc XRS (Bio-Rad) and the MultiAnalyst software.

\section{Immunofluorescence microscopy}

B. subtilis strains (PY79, KH17, KH10 and KH23) were induced to sporulate by the exhaustion method [27]. Samples were collected at different times after the onset of sporulation and fixed directly in the medium as described by Harry et al., [33], with the following modifications: after suspension in GTE-lysozyme $(50 \mathrm{mM}$ glucose, $20 \mathrm{mM}$ Tris- $\mathrm{HCl}$ [pH 7.5], $10 \mathrm{mM}$ EDTA, 2 $\mathrm{mg}$ of lysozyme $/ \mathrm{ml})$, samples $(30 \mu \mathrm{l})$ were immediately applied to microscope slide previously coated with $0.01 \%$ (wt/vol) poly-L-lysine (Sigma). After $3 \mathrm{~min}$, the liquid was removed and the microscope slide allowed to dry ( $2 \mathrm{~h}$ at room temperature). The microscope slides were washed three times in phosphate-buffered saline (PBS) (pH 7.4), blocked for 30 min with 3\% milk in PBS at room temperature and then washed nine more times with PBS. Samples were incubated overnight at $4^{\circ} \mathrm{C}$ with anti-UreA antibody (raised in mouse), washed ten times, and then incubated with anti-mouse IgG-TR conjugates with Texas Red or sulphorhodamine 101 acid chloride (Santa Cruz Biotechnology, Inc.) for $2 \mathrm{~h}$ at room temperature. After ten washes the coverslip was mounted onto a microscope slide and viewed using an Olympus BX51 fluorescence microscope using the same exposure time for all samples. Images were captured using a Olympus DP70 digital camera, processed with analySIS software and saved in TIFF format.

\section{Purification of UreA and antibody production}

The ureA gene of $H$. acinonichis was PCR amplified using chromosomal DNA as a template and oligonucleotides hisureA-up and hisureA-dn (Table 3) as primes. DNA encoding six histidines (His6-tag) was carried by oligonucleotide hisureA-dn. The obtained PCR product of 737 bp was digested with enzymes KpnI and NheI and cloned into the commercial vector $\mathrm{pBAD}$ (Stratagene). The resulting plasmid, pMD1, was verified by restriction analysis and nucleotide sequencing. pMD1 was used to transform the $E$. coli strain DH5 $\alpha$ and the recombinant strain used to overproduce UreA by addition of arabinose
$0.05 \%$. A $27 \mathrm{kDa}$ protein was visualized on a blue-coomassie stained gel and purified on Ni-NTA superflow agarose (Qiagene) followed by gel filtration on Superose 6 resin. $0.7 \mathrm{mg}$ of pure UreA protein were obtained from 3 liters of culture. For antibody production six C57BL/6J mice were immunised intraperitoneally with $30 \mu \mathrm{g}$ of purified UreA per mouse with incomplete Freund's adjuvant in a total volume of $300 \mu$ l. The injections took place at day $0,14,35$ and 56 . At day 24 and 45 sera samples were taken by tail bleeding. At day 66 total blood was collected. Obtained sera were tested against purified protein and optimal dilution of anti-UreA sera was established as 1:100 000 for western blot analysis.

\section{Acknowledgements}

We are grateful to Antonio Mazzone and Assunta Pelosi for the construction of pGEM-CotB and pGEM-CotC, respectively and to Luciano Di lorio for technical assistance. KH was supported by the Polish Ministry of Science and Higher Education on the Support for International Mobility of Scientists Program (project $n^{\circ} 23 / \mathrm{MOB} / 2007 / 0$ ). This work was supported by a grant (KBBE-2007-207948) from the EU $7^{\text {th }}$ Framework to E.R.

\section{Author details}

Department of Structural and Functional Biology, Federico II University of Naples, via Cinthia 4, Naples 80126, Italy. ${ }^{2}$ Department of Medical Biotechnology, Intercollegiate Faculty of Biotechnology UG-MUG, Dębinki 1, Gdańsk 80-211, Poland. ${ }^{3}$ Tri-City Animal Laboratory, Medical University of Gdańsk, Dębinki 1, Gdańsk 80-211, Poland.

\section{Authors' contributions}

$\mathrm{KH}$ - performed most of the experiments; RI - contributed to the immunofluorescence experiment and to the analysis of dot blot experiments; MD - purified UreA and analyzed it by western blotting; JK cloned the ureA gene of $\mathrm{H}$. acinonychis; $\mathrm{Al}$ - contributed to manuscript writing; GPS - prepared the anti-UreA antibody in mice; MDF - contributed to experiment design and manuscript writing; $\mathrm{MO}$ - contributed to experiment design and manuscript writing; ER - contributed discussions and suggestions during the work and wrote most of the manuscript. All authors read and approved the final manuscript.

\section{Competing interests}

The authors declare that they have no competing interests.

\section{Received: 3 November 2009}

Accepted: 18 January 2010 Published: 18 January 2010

\section{References}

1. Richins RD, Kaneva L, Mulchandani A, Chen W: Biodegradation of organophosphorus pesticides by surface-expressed organophosphorus hydrolase. Nat Biotechnol 1997, 15:984-987.

2. Stahl S, Uhlen M: Bacterial surface display: trends and progresses. Trends Biotechnol 1997, 15:185-192.

3. Lee SY, Choi JH, Xu Z: Microbial cell-surface display. Trends Biotechnol 2003, 21:45-52.

4. Isticato R, Cangiano G, Tran TH, Ciabattini A, Medaglini D, Oggioni MR, De Felice M, Pozzi G, Ricca E: Surface Display of Recombinant Proteins on Bacillus subtilis Spores. J Bacteriol 2001, 183:6294-6301.

5. Mauriello EMF, Duc LH, Isticato R, Cangiano G, Hong HA, De Felice M, Ricca E, Cutting SM: Display of Heterologous Antigens on the Bacillus subtilis Spore Coat Using CotC as a Fusion Partner. Vaccine 2004, 22:1177-1187.

6. Kim JH, Lee CS, Kim BG: Spore-displayed streptavidin: a live diagnostic tool in biotechnology. Biochem Biophys Res Comm 2005, 331:210-214

7. Kwon SJ, Jung HC, Pan JG: Transgalactosylation in a water-solvent biphasic reaction system with beta-galactosidase displayed on the surfaces of Bacillus subtilis spores. Appl Environ Microbiol 2007, 73:2251-2256. 
8. Henriques AO, Moran CP Jr: Structure, Assembly, and Function of the Spore Surface Layers. Ann Rev Microbiol 2007, 61:555-588.

9. Isticato R, Cangiano G, De Felice M, Ricca E: Display of Molecules on the Spore Surface. Bacterial Spore Formers Norfolk, UK: Horizon BiosienceRicca E, Henriques AO, Cutting SM 2004, 193-200.

10. Hong HA, Duc LH, Cutting SM: The use of bacterial spore formers as probiotics. FEMS Microbiol Rev 2005, 29:813-835.

11. Isticato R, Esposito G, Zilhão R, Nolasco $S$, Cangiano G, De Felice $M$, Henriques AO, Ricca E: Assembly of Multiple CotC Forms into the Bacillus subtilis Spore Coat. J Bacteriol 2004, 186:1129-1135.

12. Isticato R, Pelosi A, Zilhao R, Baccigalupi L, Henriques AO, De Felice M, Ricca E: CotC-CotU heterodimerization during assembly of the Bacillus subtilis spore coat". J Bacteriol 2008, 190:1267-1275.

13. Duc LH, Hong HA, Atkins HS, Flick-Smith HC, Durrani Z, Rijpkema S, Titball RW, Cutting SM: Immunization against antrax using Bacillus subtilis spores expressing the anthrax protective antigen. Vaccine 2007, 25:346-355.

14. Hoang TH, Hong HA, Clark GC, Titball RW, Cutting SM: Recombinant Bacillus subtilis expressing the Clostridium perfringens alpha toxoid is a candidate orally delivered vaccine against necrotic enteritis. Infec Immun 2008, 76:5257-5265.

15. Isticato R, Scotto Di Mase D, Mauriello EMF, De Felice M, Ricca E: Amino terminal fusion of heterologous proteins to CotC increases display efficiencies in the Bacillus subtilis spore system. BioTechniques 2007, 42:151-156.

16. Zhou Z, Xia H, Hu X, Huang Y, Li Y, Li L, Ma C, Chen X, Hu F, Xu J, Lu F, Wu Z, Yu X: Oral administration of a Bacillus subtilis spore-based vaccine expressing Clonorchis sinensis tegumental protein $22.3 \mathrm{kDa}$ confers protection against Clonorchis sinensis. Vaccine 2008, 26:1817-1825.

17. Corthesy-Theulaz IE, Hopkins S, Bachmann D, Saldinger PF, Porta N, Haas R, Zheng-Xin Y, Meyer TF, Bouzourene H, Blum AL, Kraehenbuhl JP: Mice are protected from Helicobacter pylori infection by nasal immunization with attenuated Salmonella typhimurium phoPc expressing urease A and B subunits. Infect Immun 1998, 66:581-586.

18. Sacco M, Ricca E, Losick R, Cutting SM: An additional GerE-controlled gene encoding an abundant spore coat protein from Bacillus subtilis. J Bacteriol 1995, 177:372-377.

19. Dailidiene D, Dailide G, Ogura K, Zhang M, Mukhopadhyay AK, Eaton KA Cattoli G, Kusters JG, Berg DE: Helicobacter acinonychis: Genetic and Rodent Infection Studies of a Helicobacter pylori-Like Gastric Pathogen of Cheetahs and Other Big Cats. J Bacteriol 2004, 186:356-365.

20. Gomez-Duarte OG, Lucas B, Yan ZX, Panthel K, Haas R, Meyer TF: Protection of mice against gastric colonization by Helicobacter pylori by single oral dose immunization with attenuated Salmonella typhimurium producing urease subunits A and B. Vaccine 1998, 16:460-471.

21. Londono-Arcila P, Freeman D, Kleanthous $H$, O'Dowd AM, Lewis $S$ Turner AK, Rees EL, Tibbitts TJ, Greenwood J, Monath TP, Darsley MJ: Attenuated Salmonella enterica serovar Typhi expressing urease effectively immunizes mice against Helicobacter pylori challenge as part of a heterologous mucosal priming-parenteral boosting vaccination regimen. Infect Immun 2002, 70:5096-5106.

22. Bumann D, Metzger WG, Mansouri E, Palme O, Wendland M, Hurwitz R Haas G, Aebischer T, von Specht BU, Meyer TF: Safety and immunogenicity of live recombinant Salmonella enterica serovar Typhi Ty21a expressing urease $A$ and $B$ from Helicobacter pylori in human volunteers. Vaccine 2001, 20:645-652.

23. DiPetrillo MD, Tibbetts T, Kleanthous H, Killeen KP, Hohman EL: Safety and immunogenicity of phoP/phoQ-deleted Salmonella typhi expressing Helicobacter pylori urease in adult volunteers. Vaccine 1999, 18:449-459.

24. Rizos K, Lattemann CT, Bumann D, Meyer TF, Aebischer T: Autodisplay: Efficacious Surface Exposure of Antigenic UreA Fragments from Helicobacter pylori in Salmonella Vaccine Strains. Infect Immun 2003, 71:6320-6328.

25. Ferrero RL, Thiberge JM, Huerre M, Labigne A: Recombinant antigens prepared from the urease subunits of Helicobacter spp.: evidence of protection in a mouse model of gastric infection. Infect Immun 1994, 62:4981-4989.

26. Michetti P, Corthesy-Theulaz I, Davin C, Haas R, Vaney AC, Heitz M, Bille J, Kraehenbuhl JP, Saraga E, Blum AL: Immunization of BALB/C mice against Helicobacter felis infection with Helicobacter pylori urease. Gastroenterology 1994, 107:1002-1011.
27. Cutting S, Horn Vander PB: Genetic analysis. Molecular Biological Methods for Bacillus John Wiley and Sons, Chichester, UKHarwood C, Cutting S 1990, 27-74.

28. Cutting SM, Hong HA, Baccigalupi L, Ricca E: Oral Vaccine Delivery by Recombinant Spore Probiotics. Intern Rev Immunol 28:487-505.

29. Sambrook J, Fritsch EF, Maniatis T: Molecular cloning: a laboratory manual. Cold Spring Harbor Laboratory Press, Cold Spring Harbor, N.Y, 21989

30. Julkowska D, Obuchowski M, Holland IB, Séror SJ: Comparative analysis of the development of swarming communities of Bacillus subtilis 168 and a natural wild type: critical effects of surfactin and the composition of the medium. J Bacteriol 2005, 187:65-76.

31. Nicholson WL, Setlow P: Sporulation, germination and outgrowth. Molecular biological methods for Bacillus John Wiley \& Sons, Ltd., Chichester, United KingdomHarwood C, Cutting S 1990, 391-450.

32. Monroe A, Setlow P: Localization of the transglutaminase cross-linking sites in the Bacillus subtilis spore coat protein GerQ. J Bacteriol 2006, 188:7609-16

33. Harry EJ, Pogliano K, Losick R: Use of immunofluorescence to visualize cell-specific gene expression during sporulation in Bacillus subtilis. J Bacteriol 1995, 177:3386-3393.

34. Youngman P, Perkins JB, Losick R: A novel method for the rapid cloning in Escherichia coli of Bacillus subtilis chromosomal DNA adjiacent to Tn917 insertion. Mol Gen Genet 1984، 195:424-433.

doi:10.1186/1475-2859-9-2

Cite this article as: Hinc et al.: Expression and display of UreA of Helicobacter acinonychis on the surface of Bacillus subtilis spores. Microbial Cell Factories 2010 9:2.

\section{Submit your next manuscript to BioMed Central and take full advantage of:}

- Convenient online submission

- Thorough peer review

- No space constraints or color figure charges

- Immediate publication on acceptance

- Inclusion in PubMed, CAS, Scopus and Google Scholar

- Research which is freely available for redistribution
Biomed Central 